\title{
Distance Learning During the Pandemic Period of COVID-19 with Zoom and Webex Comparison
}

\author{
Harry Dhika ${ }^{1}$, Fitriana Destiawati ${ }^{2}$, Surajiyo $^{3}$, Musa Jaya ${ }^{4}$ \\ Department of Engineering and Computer Science, \\ Indraprasta PGRI University, Indonesia ${ }^{1,2,3,4}$ \\ \{dhika@unindra.ac.id¹, honeyzone86@gmail.com², surajiyo@unindra.ac.id², \\ musajaya.here@gmail.com ${ }^{4}$ \}
}

\begin{abstract}
During the pandemic, COVID-19 affected all aspects of life, one of which was affected was the field of education. With large-scale social restrictions causing all academic activities to be hampered. Learning activities must continue to run during this pandemic, the effort being made is to do distance learning or electronic learning, which is better known as e-learning. Technology for education that plays an important role in dealing with this pandemic is the learning management system as a form of learning methods in the COVID-19 pandemic. In this study distance learning in the COVID-19 pandemic with the comparison of Zoom and Webex can be relevant to the concept of applying learning methods in the face of a pandemic, which aims to provide convenience in the use of technology for education. The results of this study are to provide an understanding of learning methods that can be applied in learning activities as an effort to deal with the COVID-19 pandemic that can be used by schools in Indonesia, by knowing the comparison is expected to provide convenience in using Zoom and Webex in distance learning at this time.
\end{abstract}

Keywords: Learning Management System, Learning Media, E-Learning, Video Conference

\section{Introduction}

The development of technology can provide new methods in learning activities, this is certainly related to the place or process of teaching and learning for students and teachers. Learning media as a means of delivering learning material. During the COVID-19 pandemic[1]-[3], the learning activities could not be carried out as usual because academic activities in schools could lead to wider dissemination, the application of large-scale social restrictions required learning activities to be carried out at home, this transition could not be avoided by anyone so readiness was needed to adjust to the pandemic period of COVID- 19 . Information and communication technology (ICT) renders a technological solution to these practical difficulties [4] e-learning is a media developed for educational institutions, which aims to support online learning. This makes it easy for teachers to use technology as a support for learning activities that are specific so that learning can take place well even though it is done remotely. Students can utilize technology for learning activities, so it is more efficient to 
use electronic learning which is used as a source of learning activities, as a means of delivering and evaluating material.

The LMS on which we increasingly rely as a means of learning have a considerable potential in the construction of knowledge and competence development [5]. E-learning has expanded rapidly with a variety of technologies and devices to access learning resources, such as laptops, computers, smartphones, and tablets. Technology has profoundly impacted education and learning and teaching methods [6]. Through e-learning, the process of learning activities undertaken can take place remotely without having to face-to-face in the classroom. E-learning content providers must attract learners with appropriate e-learning content and they have to adequately incorporate e-learning services and technologies in the e-learning process [7]. With the development of technology and the availability of the internet, this electronic learning system can be implemented well as a better potential in learning activities during the COVID-19 pandemic. E-learning provides features that can be used in learning activities that are already available to teachers and students. Students can access and use interactively the various sources of information available to them anywhere, anytime.

Learning activities can be carried out using video conferencing applications such as Zoom and Webex, from these applications that can facilitate learning activities that can optimize the process of understanding and delivering material. This learning method is an effective way to deliver learning material, learning concepts that prioritize ease of access to place and time. The functions offered for each application and also the interface provided for each application have different functions, so that compatibility can be used as needed. To do activities and other activities such as planning, implementation, and evaluation, you can use Moodle as a medium for managing learning activities. In this context, Webex is integrated with Moodle which forms concepts as virtual learning, where the distance learning process is a new learning framework for solving educational problems during the COVID-19 pandemic.

\section{Method}

Research conducted based on a qualitative descriptive approach, which examines the status of an object, conditions, systems of thought, function and perception. Because it does not use calculations in this research study. Literacy studies are also a method in gathering various sources of books, articles and journals and documents related to research. The method is a method that requires a lot of activity reading data, analysis and information that has been collected. The writing method used in the form of collecting materials in the form of theory taken from the results of the analysis obtained in the application of distance learning or elearning that is applied by high school teachers in Java-Bali, the object of this study is the teacher and students.

\section{Discussion}

Distance learning can be accomplished with the presence of an LMS (Learning Management System), an e-learning platform is a software that includes various services that help teachers manage their courses [5] an application used in making the learning media process directly as software for the delivery of learning activities programs, facilities provided by the LMS also take the form of learning course management, learning material management, activity management, value management, displaying transcript values and managing display 
for e-learning. In LMS, mediation involves the acquisition of competencies and communication skills of all teachers and students, and greater concern for the creation of moments of interaction and the possible practical application of collaborative work, that with the learning process occurs participative [8]. Advances in information and communication technologies offer new opportunities [9] this analysis starts with the most powerful and commonly used tools for synchronous distance e-learning [10] namely Zoom and Webex. The use of Zoom and Webex can provide convenience in the delivery of learning material during the COVID-19 pandemic, this does not rule out the possibility of using the internet in Indonesia with good distance learning conducted, based on statistical data from Hootsuite and We Are Social and the use of the internet with devices used in Indonesia.

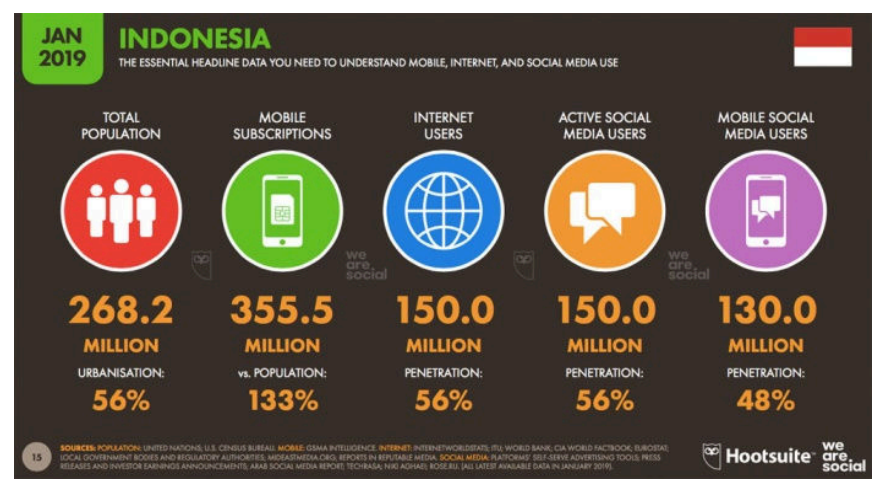

Fig. 1. The Essential Headline Data Media Use

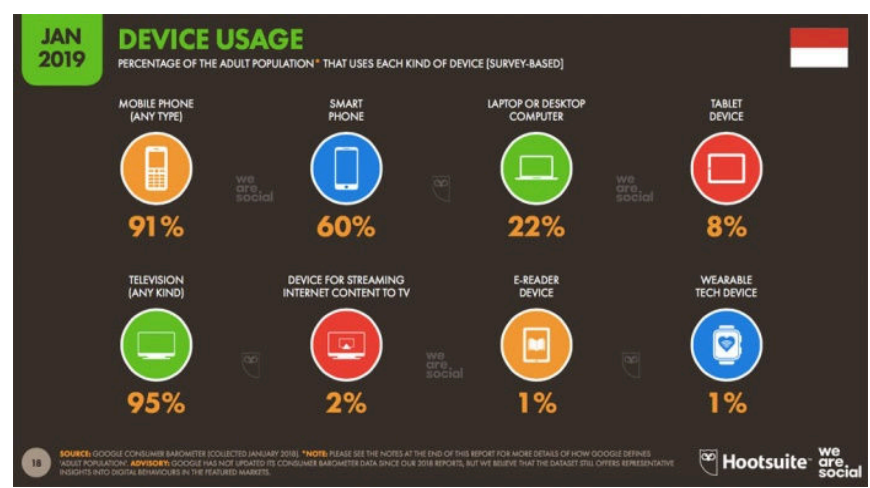

Fig. 2. Percentage Uses Each Kind of Device

\subsection{Zoom}

Zoom is a collaborative cloud-based video conferencing service offering features including online meetings, group messaging services, and secure session recording. Zoom offers the ability to communicate in real-time with individuals who are geographically dispersed via a computer, tablet or mobile device. The video conferencing application used is Zoom [11] learning activities can be done through Zoom with face to face system directly in different places. Other important security features include user-specific authentication, real-time encryption of meetings, and the ability to backup recordings to online remote server networks ("the cloud") or local drives, which can then be shared securely for the purpose of 
collaboration [9]. This learning activity can be done by teachers and students or students with students to discuss the material and assignments delivered, Zoom has a complete feature with distance learning needs.

Zoom provides certainty in the presence and participation of students in online classes conducted by the teacher, the teacher can record the implementation of learning activities carried out as evidence of the teacher's performance of teaching and learning activities. Teachers can share screens to display slide presentations or videos or files that can be seen by all students present in the online class. Chat and file sharing features are available for teachers and students so that online learning activities can be carried out properly and optimally.

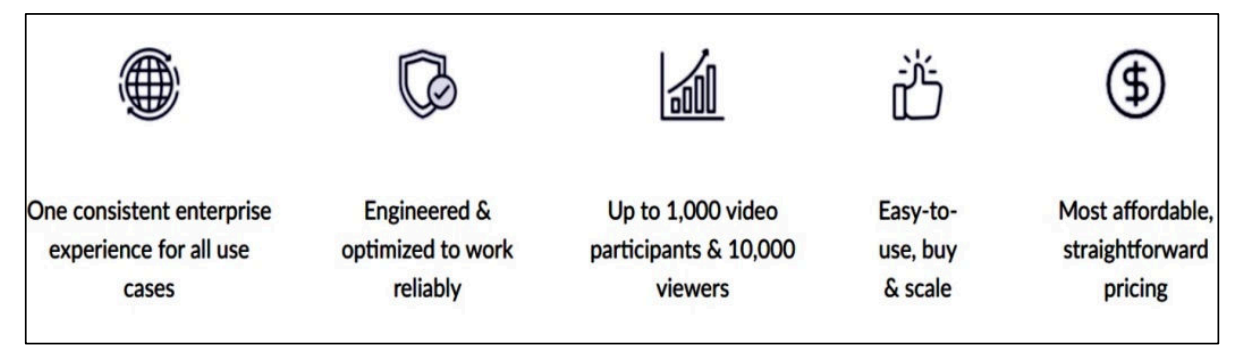

Fig. 3. Zoom Advantage

Tabel 1. Zoom Feature

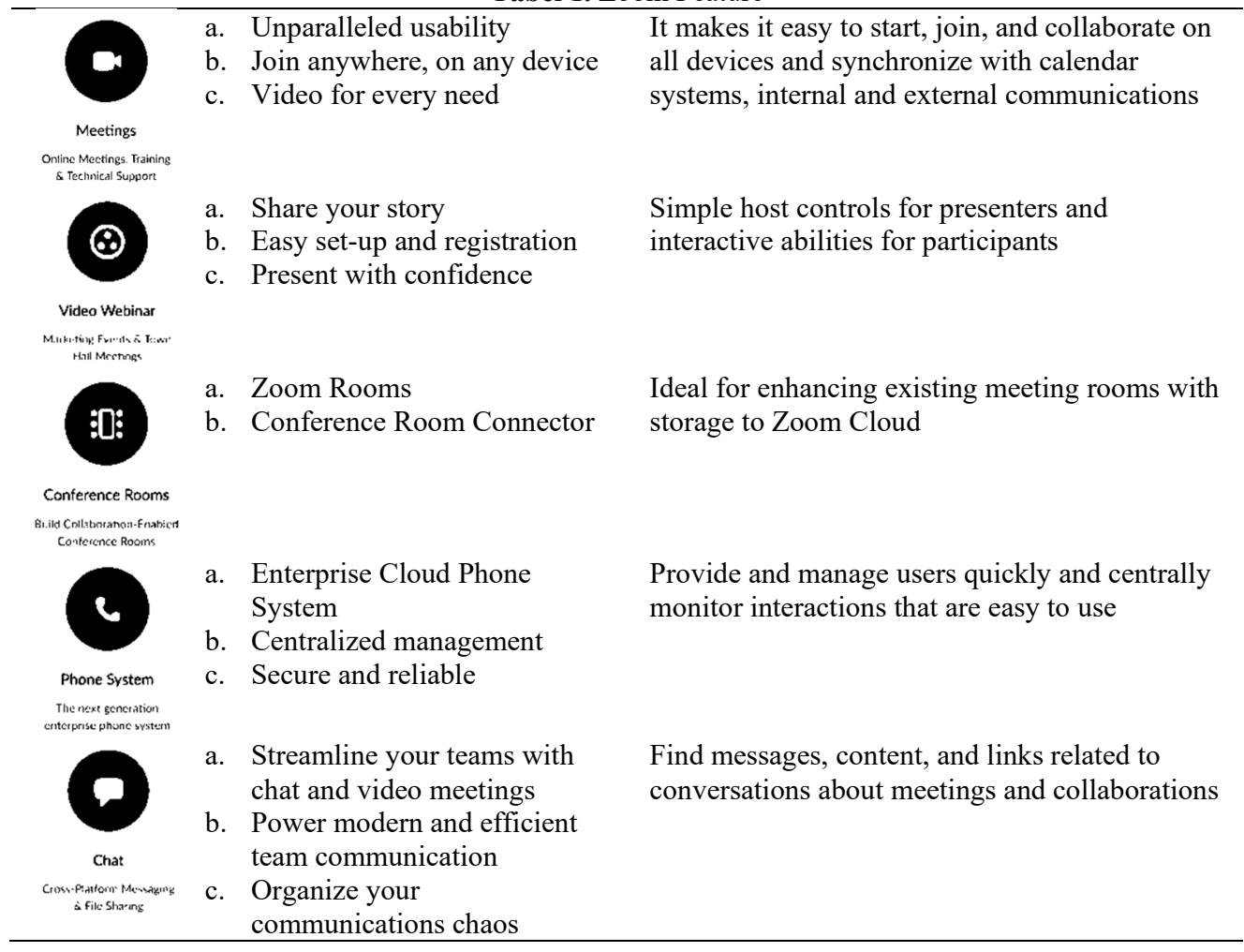




\subsection{Webex}

Webex is a video-conferencing application that enables online communication using personal and mobile devices such as computers, tablets or mobile devices while it is still within the reach of the internet network. Webex features interactive capabilities such as screen sharing, the ability to annotate documents andwrite on a virtual whiteboard, as well as the option to join meetings from a computer, smartphone, or tablet [12]. Webex has advantages that can be integrated with LMS to facilitate the use of virtual classrooms and online learning by managing activities and other activities such as planning, implementation, and evaluation. One LMS that can be used for Webex integration is Moodle-based e-learning.

The use of Webex can arrange or join classes or online meetings through cellphone or computer devices, teachers can share screens in online classes to facilitate and provide certainty in the presence and participation of students in online classes that are carried out, students can be invited as much as possible according to the needs of learning activities . Learning activities in Webex can be recorded for the needs of teaching and learning activities, as evidence of teacher performance and material for students who do not participate in online classes. With video and audio conferencing in high quality and integrated with email services such as Gmail, Outlook and Office 365.

Tabel 2. Webex Advantage \& Features

\begin{tabular}{|c|c|}
\hline Started with remote education & $\begin{array}{l}\text { a. Live class to learn } \\
\text { b. Class to learn in education }\end{array}$ \\
\hline $\begin{array}{l}\text { a. Learn to teach virtually } \\
\text { b. Course content to the virtual } \\
\text { classroom }\end{array}$ & $\begin{array}{l}\text { a. Virtual classroom } \\
\text { b. Setting remote student expectations } \\
\text { c. Managing a remote classroom culture }\end{array}$ \\
\hline Futher skills & $\begin{array}{l}\text { a. Scheduling meeting } \\
\text { b. Class engaged } \\
\text { c. Class more accessible }\end{array}$ \\
\hline $\begin{array}{l}\text { Integrate Webex into Learning } \\
\text { Management System (LMS) }\end{array}$ & $\begin{array}{l}\text { a. Take a live class to learn Webex in LMS } \\
\text { b. Set up Webex in LMS page }\end{array}$ \\
\hline $\begin{array}{l}\text { a. Webinars } \\
\text { b. Webcasting } \\
\text { c. Online learning } \\
\text { d. Remote support }\end{array}$ & $\begin{array}{l}\text { a. End-to-end online events } \\
\text { b. Record everything } \\
\text { c. Scale reach } \\
\text { d. Engaging, interactive online training }\end{array}$ \\
\hline
\end{tabular}

\subsection{Zoom and Webex}

Comparison of this video conferencing application, both of which provide ease of use especially for education, namely distance learning, both of which provide features that function very well for the implementation of learning during the COVID-19 pandemic. Zoom and Webex are the top two video conferencing tools that can be used to enhance distance learning activities, a detailed comparison between Zoom and Webex to choose the best option. 
Table 3. Comparison Of Video Conference Applications

\begin{tabular}{lll}
\hline & \multicolumn{1}{c}{ Zoom } & \\
& & \\
\hline Participants & Up to 100 Participants & Up to 500 Participants \\
User Interface & Simple & Complex \\
Support & Online Support for free, phone for & Online for free, Phone Support During \\
& paid, Account Manager for Enterprise & Business Hours up to 24-7 for Enterprise \\
Conferencing & HD Video, HD Voice, Screen & HD Video, Screen Sharing, \\
Features & Sharing, Whiteboarding & Whiteboarding \\
Web Features & Private \& Group Chats, MP4 or M4A & Multimedia Content Sharing, Local \\
& Local Recording, Host Controls, & Recording, Host Controls Toll-Free Dial-In \\
Cupport & Chrome \& Outlook Plug-Ins & \\
Gntegrations & Eoogle Drive, Pardot, Dropbox, & Microsoft Office, Google Calendar, \\
& Mloqua, HubSpot, Infusionsoft \& & Facebook Live \& More \\
Security & Eore & \\
Features & Both Encryption and User Authentication & Security Control, Encryption and User \\
& Transmission and Storage & Authentication, Both Encrypt Meetings, \\
Basic Price & Free - \$19.99/month & Transmission and Storage \\
\hline
\end{tabular}

\section{Conclusion}

The COVID-19 pandemic period requires schools to apply a learning method based on technology, communication, and information, so that distance learning can be created to reduce the impact of the spread of COVID-19. LMS can implement electronic learning or called e-learning, by creating an effective learning system during the COVID-19 pandemic, the application of distance learning with video conferencing applications is very important in learning activities by providing certainty in the presence and participation of students in online classes that implemented by the teacher. Zoom and Webex are two of the top video conferencing tools that can be used to enhance distance learning activities to create and create learning conditions for students and make it easier for teachers to provide knowledge and teaching to be better, and more perfect in the pandemic period of COVID-19.

The use of video conferencing applications can be applied in schools as an effective and efficient learning media, without being tied to places making access easier in learning that can be done at home. In the case of the development of instructional media requires human resources who can manage online learning activities and understand technology, this is related to facilities that can support the education system that applies distance learning. The use of elearning, facilities in the form of e-learning and development can be spread evenly throughout schools in Indonesia.

\section{Acknowledgements}

Appreciation and gratitude to the Directorate of Research and Community Service, Director General of Research and Development Strengthening, Ministry of Research, Technology and Higher Education which has funded the Higher Education Research Application Program (PTUPT) in 2020 with the title: "Application and Development of Moodle in Learning Activities". Thanks also to LLDIKTI Wilayah III Jakarta and the Institute 
of Research and Community Service at Indraprasta PGRI University for helping this research activity through Research Contracts.

\section{References}

[1] M. I. Ardura, D. M. Hartley, C. Dandoy, L. Lehmann, S. Jaglowski, and J. J. Auletta, "Addressing the impact of the Coronavirus Disease (COVID-19) pandemic on hematopoietic cell transplantation: Learning networks as means for sharing best practices," Biol. Blood Marrow Transplant., vol. 000, 2020, doi: 10.1016/j.bbmt.2020.04.018.

[2] T. Favale, F. Soro, M. Trevisan, I. Drago, and M. Mellia, "Campus Traffic and eLearning during COVID-19 Pandemic," Comput. Networks, p. 107290, 2020, doi: 10.1016/j.comnet.2020.107290.

[3] N. Zhu et al., "A novel coronavirus from patients with pneumonia in China, 2019," $N$. Engl. J. Med., vol. 382, no. 8, pp. 727-733, 2020, doi: 10.1056/NEJMoa2001017.

[4] R. Shah, S. Chakrabarti, A. Sharma, S. Grover, D. Sachdeva, and A. Avasthi, "Participating from homes and offices: Proof-of-concept study of multi-point videoconferencing to deliver group parent training intervention for attention-deficit/ hyperactivity disorder," Asian J. Psychiatr., vol. 41, no. February, pp. 20-22, 2019, doi: 10.1016/j.ajp.2019.03.006.

[5] M. Ouadoud, M. Y. Chkouri, and A. Nejjari, "Learning Management System and the Underlying Learning Theories: Towards a new Modeling of an LMS," Int. J. Inf. Sci. Technol. - iJIST, vol. 2, no. 1, pp. 25-33, 2018.

[6] D. Al-Fraihat, M. Joy, R. Masa'deh, and J. Sinclair, "Evaluating E-learning systems success: An empirical study," Comput. Human Behav., vol. 102, no. March 2019, pp. 67-86, 2020, doi: 10.1016/j.chb.2019.08.004.

[7] B. Šumak, M. Heričko, M. Pušnik, and G. Polančič, "Factors affecting acceptance and use of moodle: An empirical study based on TAM," Inform., vol. 35, no. 1, pp. 91-100, 2011.

[8] P. C. de Oliveira, C. J. C. de A. Cunha, and M. K. Nakayama, "Learning Management Systems (LMS) and e-learning management: an integrative review and research agenda," J. Inf. Syst. Technol. Manag., vol. 13, no. 2, pp. 157-180, 2016, doi: 10.4301/s1807-17752016000200001.

[9] M. M. Archibald, R. C. Ambagtsheer, M. G. Casey, and M. Lawless, "Using Zoom Videoconferencing for Qualitative Data Collection: Perceptions and Experiences of Researchers and Participants," Int. J. Qual. Methods, vol. 18, pp. 1-8, 2019, doi: 10.1177/1609406919874596.

[10] D. F. García, C. Uria, J. C. Granda, F. Suárez, and F. González, “A Functional Evaluation of the Commercial Platforms and Tools for Synchronous Distance eLearning," Proc. 3rd WSEAS/IASME Int. Conf. Educ. Technol. (EDUTE 2007), pp. 330-335, 2007.

[11] L. Z. Cai et al., "Accuracy of remote burn scar evaluation via live video-conferencing technology," Burns, pp. 4-11, 2016, doi: 10.1016/j.burns.2016.11.006.

[12] R. M. Gordon, "Debriefing Virtual Simulation Using an Online Conferencing Platform: Lessons Learned," Clin. Simul. Nurs., vol. 13, no. 12, pp. 668-674, 2017, doi: 10.1016/j.ecns.2017.08.003. 